\title{
Freckle Formation in Superalloys
}

\author{
P. Auburtin, S. L. Cockcroft, A. Mitchell and T. Wang \\ Advanced Materials and Process Engineering Laboratory \\ University of British Columbia \\ Vancouver V6T 1 Z4 BC \\ Canada
}

\begin{abstract}
The analysis of the formation mechanisms for freckling and for random grain formation in single crystal castings has resulted in a general understanding of the principles involved, but has not been tested extensively against results in actual superalloy castings. In this work, we present the results of experimental work on the production of freckling in superalloy castings, made directionally in a Bridgeman furnace capable of producing DS castings in which the directional axis can be rotated with respect to gravity. The results indicate that we may account quantitatively for freckle formation through an analysis based on fluid-flow as described by a modified Rayleigh criterion. The theoretical critical condition for freckle initiation is found to be a Rayleigh Number of unity; the experimental determination of this critical value is found to be in the region of $0.7-0.9$ depending on the alloy examined. We ascribe the difference in these values to the secondary features of the dendrite morphology.

The relation to random grain nucleation is found to lie in the role of isotherm curvature in the solidifying region. This aspect is examined by the use of ProCAST computations in both castings and remelt ingots.
\end{abstract}

\section{Introduction}

The problem of freckle generation in castings is a very old one and has been studied by a number of workers $(1-3)$. The general mechanism for the formation of the defect has been defined as bouyancy-driven flow in the liquid/solid region of the casting, and the analysis of this mechanism for low temperature systems, including aqueous analogues, has confirmed the fundamental parameters as a balance between the bouyancy driving-force and the resistance offered by the dendrite mesh in the mushy zone. The balance was quantified by Sarazin and Hellawell (4) in terms of the system's Rayleigh Number (Ra); a proposal which was verified by experimental work on a low melting alloy system. Further experimental work by Auburtin et al (5) on a range of segregation-sensitive superalloys confirmed the validity of this approach. In this latter work, several interesting features of the analysis were highlighted. First, it is interesting to note that the necessary bouyancy force is developed from extremely small density gradients in the segregating liquid, of the order of $0.001 \mathrm{~g} / \mathrm{mm}$, and is thus quite difficult to determine experimentally or compute from existing thermophysical databases. Second, the Rayleigh Number as defined by the above workers contains a high order of dendrite spacing and is thus very sensitive to the structure developed during solidification. Although the superalloys all have very similar solidification characteristics in respect of fractionsolid as a function of temperature (6), small differences in dendrite morphology may have a large influence on the numerical value of $\mathrm{Ra}$, and therefore on the development of freckling in a casting. Thirdly, the common industrial solution to freckling in directional castings, that of increasing the solidification temperature gradient, is shown to be reasonable in that its primary influence is on the dendrite spacing, but it is also seen to have clear limitations in the case of large thermal sections as would, for example, exist in large castings. Finally, the role of casting geometry and imperfect isotherm control during solidification is not at present part of the analysis and should be included for a full description of the phenomenon.

There is a putative link between freckling and the development of random grains in single crystal castings, based on two hypotheses. The first (7) relies on the existence of quite shallow temperature gradients in the vicinity of the liquidus surface which permits the development of substantial constitutional supercooling. At the same time, the liquid flow in the freckle channel is held to detach secondary or tertiary dendrite arms by a solution mechanism. The dendrite fragments are carried into the liquidus region and are able to nucleate new grain growth. The hypothesis is supported by the presence of both grain fragments and random grains in experimental castings which contain freckles. The second (8) links the two phenomena by the presence of isotherm curvature in the solidification region of the casting. The curvature, as shown below, provides an additional factor to the bouyancy driving force for freckle formation. At the same time, the curvature implies an increased undercooling in the surface region of the casting which heightens the probability of grain nucleation. This mechanism is supported by experimental work, reported below, on freckle formation, and also by the presence of random grains in castings which do not contain freckles, where the undercooling provoked by the curvature is sufficient for grain nucleation, but insufficient for freckle formation in the alloy composition concerned. The work reported in this paper is a contribution to these developments.

\section{Experimental}

The experimental basis for the work is a series of experimental castings made using a Bridgeman furnace of an unusual design. The furnace has been described previously (9), and is designed to cast cylindrical samples under carefully controlled conditions of temperature and withdrawal rate. The unusual design feature is that the furnace may be titled to an angle of $40^{\circ}$ to the horizontal without changing the direction of the isotherms in relation to the axis of the casting. The alloys chosen for this study cover both casting and forging compositions as shown in Table 1.
Supcralloys 2000

Edited by T.M. Pollock, R.D. Kissinger, R.R. Bowman,
K.A. Green, M. McLean, S. Olson, and J.J. Schirra

K.A. Green, M. McLean, S. Olson, and J.J. Schirra
TMS (The Minerals, Metals \& Materials Society), 2000 
The alloys were solidified directionally as $2 \mathrm{~cm}$ dia cylinders approximately $150 \mathrm{~mm}$ long with a range of temperature gradients and rates, and the castings examined for freckle formation (10). The results are summarised in Table 2, demonstrating that the freckling phenomenon can be activated by increasing the angular driving force. For each of the alloys, the freckle composition was analysed (Table 3) in order to compute the liquid density; the average liquid density during solidification was also computed from a combination of previously-established segregation coefficients (9) and the software package "METALS" (11).

\section{Discussion}

Using the modified Rayliegh Number as developed by Auburtin et al (8)

$$
R a=\frac{g d \rho / d z}{\eta D_{T}}\left[\lambda_{1}\left(\frac{K}{K_{y}}\right)\right]^{4}
$$

where

$R a=$ Rayleigh Number;

$g=$ Gravitational Constant $\left(\mathrm{ms}^{-2}\right)$;

$d \rho / d z=$ Density Inversion Term in Vertical Direction $\left(\mathrm{kgm}^{-4}\right)$;

$\eta=$ Dynamic Viscosity $\left(\mathrm{kgm}^{-1} \mathrm{~s}^{-1}\right)$;

$D_{T}=$ Thermal Diffusivity $\left(\mathrm{m}^{2} \mathrm{~s}^{-1}\right)$;

$\lambda_{I}=$ Primary Dendrite Arm Spacing $(\mathrm{m})$;

$K=$ Permeability in Vertical Direction $\left(\mathrm{m}^{2}\right)$. (8)

$K_{y}=$ Permeability Parallel to Primary Dendrite Arm $\left(\mathrm{m}^{2}\right)$. (8)

we may derive a threshold value for the freckle formation as shown in Table 2. It is seen from this analysis that whilst the threshold value can be used to predict areas in a casting which would be sensitive to freckle formation, there remains an alloy dependence which is not covered by parameters contained in the Rayleigh Number as formulated above. Since the relation between fraction solid and relative temperature between liquidus and solidus is approximately constant for all superalloys (Figure 1) we cannot assign this sensitivity to a difference in the volume fraction of dendrite present at the freckle site. However, dendrite shape is not constant throughout the superalloy composition range, and is it possible that the variation observed originates in a "shape factor" depending on the detailed shape of the secondary and tertiary dendrite arms.

The composition variations on a base of IN718 illustrate two points. First, that the flow system causing freckling is the same basic process whether the liquid rises or falls through the dendrite network. A threshold value can be derived for the type of freckling described (12) in the same way as for the classic mechanism. Second, the role of the silicon content is well demonstrated in that since it is a highly segregating light element, its concentration determines the direction of the bouyancy force and hence also the morphology of the resulting freckle. In principle, carbon can be shown to behave in the same manner, as has been observed in the case of the high-speed steels (8), but with the complication of concentration changes prompted by the precipitation of primary carbides.

Since the freckling mechanism is the same in both ingot and casting manufacture, the criteria developed above should be able to account for the morphology of freckles found in remelted ingots. In this case the freckles are found predominantly at the mid-radius position, which is due to the balance described in the Rayleigh Number between the angular driving force and the resistance to flow offered by the dendrite structure. This balance results in a maximum freckle probability at the mid-radius position, as illustrated in Figures $2-4$, indicated by the variation of $\mathrm{Ra}$ across the radius of the ingot. In this case, uncertainty in the computation of the precise temperature gradients at the liquidus surface leads to estimates of $\mathrm{Ra}$ which are higher than the expected values of approximately unity. The form of the radial variation of $\mathrm{Ra}$, however, clearly indicates a maximum freckle probability at the mid-radius position.

Two further factors appear to be important in freckle formation, and are not accounted for by the above estimates. First, it is intuitively obvious that the freckle channel must draw liquid from a reservoir in the solidifying network, replenished by inflow from the bulk. One may speculate that this reservoir will have a minimum volume which is of the same order as that of the freckle channel itself. If this is the case, then freckles should not form if the "root" region lies in a section of the casting which is smaller than the required volume. Freckles should not develop, therefore, in casting areas where this minimum dimension is not available in all directions from the freckle "root". It is postulated that this factor is the reason why freckles are not seen on interior faces of the casting such as air-cooling passages in turbine airfoils. However, when the casting is large enough, the air channel faces will present more than the critical dimension and so we have the troublesome prospect of freckling on interior surfaces which cannot be inspected. The dimension, by reference to the freckles observed in industrial castings appears to be in the range of several $\mathrm{mm}$. A second factor which is likely to play a role in DS and forging alloys is that of second-phase precipitation. When nitrides and/or carbides are precipitated in the interdendritic liquid, the composition changes in a manner which is predictable from phase relationships, and which can be included in the Rayleigh Number computation. However, since the precipitates are of the same order of size as the interdendritic spacing, they will have an influence on the development of interdendritic fluid flow. This effect has been demonstrated in the case of the formation of microporosity in castings on INIO0 (18), and will play a role in the freckle formation mechanism through the structural component of $\mathrm{Ra}$, by increasing the interdendritic flow resistance.

Although the above description of the freckle formation mcchanism in terms of $\mathrm{Ra}$ appears to explain the features observed in practice, we must examine the extent to which the actual isotherm curvatures experienced in castings could give rise to the $\mathrm{Ra}$ values used. The role of furnace temperature and withdrawal conditions has been studied using "ProCAST" software (13) for the case of the present small cylinder and also the cases of larger castings and castings containing ceramic inserts. Some of the results obtained are presented in Figure 5 and clearly show that with relatively small changes in withdrawal conditions it is possible to produce substantial isotherm curvature. In an industrial system such changes could readily take place through small errors in estimating the relative positions of the actual liquidus front and the furnace profile. In the limiting case of very large section castings it is germane to question whether or not such curvature can be avoided at economically-viable withdrawal rates due to the thermal cross-section of the casting. It is also interesting to note that the addition of forced cooling to the system has the potential to increase the isotherm curvature if the 
correct withdrawal conditions are not precisely observed, as noted by Giamei (14) in his studies of liquid metal cooling.

The link with random grain formation through either of the two mechanisms noted above is through isotherm curvature. Estimations of the flow velocity in a freckle channel (8) lead to values at which it is feasible to envisage solid particles persisting against the dissolution process until they reach a position at the liquidus where they would melt. If the undercooling at that position is sufficient, such particles could, therefore nucleate fresh grains. The undercooling required, following the theories of Hunt et al (1515) is small, of the order of $2-3^{\circ} \mathrm{C}$. However, it is still necessary to explain the formation of random grains in castings which do not exhibit freckling. In the case of random grain nucleation produced when isotherm curvature has produced sufficient undercooling to cause nucleation on features such as mold imperfections or inclusions, the same curvature should, in principle have given rise to freckling. It appears from observation of industrial castings results that the curvature required for the former condition is less than that required for the latter in the common SX alloys, leading to the conclusion that the undercooling necessary for heterogenous nucleation is quite small. This conclusion is difficult to reconcile with the lattice mismatch theory of Hunt, since the likely surface imperfections or inclusions all have lattice mismatches which lead to undercooling requirement estimates of at least $10^{\circ} \mathrm{C}(16)$.

\section{Conclusions}

We conclude that the freckle initiation condition can be represented by an appropriate form of the Rayleigh criterion which takes into account the isotherm curvature in the system. This curvature also appears to be a significant factor in the formation of random grains and may possibly be amenable to a similar treatment. As with many similar formulations in the field of solidification, the accuracy of this analysis is dependent on the accuracy with which the appropriate physical parameters of the alloy can be defined.

\section{Acknowledgements}

The authors would like to acknowledge the valuable support ad assistance received during the course of this work from RollsRoyce plc and the Consarc Corporation. They are also grateful for the provision of alloy materials from Cannon-Muskegon Inc and the Special Metals Coroporation.

\section{References}

1. S.M. Copley, A.F. Giamei, S.M. Johnson, M.F. Hornbecker: Met. Trans., 1970, Vol. 1, pp.2193-2204.

2 M.G. Worster: Ann. Rev. Fluid Mech., 1997, 29, pp.91-122.
3. J.C. Heinrich, S. Felicelli, D.R. Poirier: Num. Heat Transfer, Part B, 1993, Vol. 23, pp.461-481.

4. J.R. Sarazin, A. Hellawell: Met. Trans. A, 1988, Vol. 19A, pp.1861-1871.

5. P. Auburtin, A. Mitchell: Liquid Metal Processing and Casting AVS Conference (Santa Fe, NM, February 1997), pp.18-34.

6. P. Auburtin: Ph.D. Thesis, University of British Columbia, Vancouver, BC, Canada, August 1998.

7. T.M. Pollock, W.H. Murphy: Met. Trans. A, 1996, Vol. 27A, pp.1081-1094.

8. P. Auburtin, T. Wang, S.L. Cockcroft, A. Mitchell: Met. Trans. $B, 2000$, to be published.

9. P. Auburtin: M.A.Sc Thesis, University of British Columbia, Vancouver, BC, Canada, August 1995.

10. T. Wang: M.A.Sc Thesis, University of British Columbia, Vancouver, BC, Canada, May 1999.

11. "METALS" software, developed by National Physical Laboratories, Teddington, Middlesex, UK.

12. W Chen, W. H. Yang, K-M Chang S K Mannan and J.J. deBarbadillo; Proc. Int. Conference on Liquid Metals, Santa Fe 1999, eds. A Mitchell et al, publ. AVS 1999, pp.122 - 130.

13. ProCAST software, User's Manual and Materials Database, developed by UES Inc., Dayton, OH, USA.

14. A.F. Giamei, B.H. Kear: Met. Trans., 1970, Vol. 1, pp.21852192.

15. J. D. Hunt, Materials Science and Engineering, Vol. 65 (1984), pp.75-83.

16. J. Fernihough, The Columnar to Equiaxed Transition in Nickel Based Superalloys AMI and MAR-M200 Hf, Ph. D Thesis; UBC, 1995.

17. A. S. Ballantyne, A. Mitchell and J-F Wadier Proc. $6^{\text {th }}$ Intl Vacuum Metallurgy Conference, 1979, eds G K Bhat and R Schlatter, publ. AVS, pp.555-571.

18. J. Lecomte-Beckers and M. lamberigts: "High temperature Alloys for Gas Turbines 1986", eds. W. Betz et al, Part I, 1986, pp.745-756. 


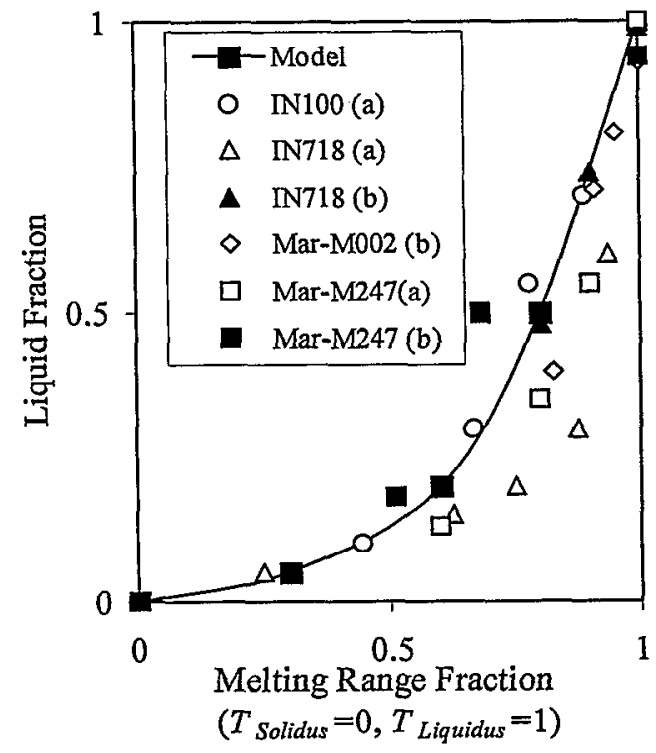

Figure 1 Typical liquid fraction profile along the mushy zone of nickel base superalloys.(experimental measurements : (a) from [9] and (b) from [17].)

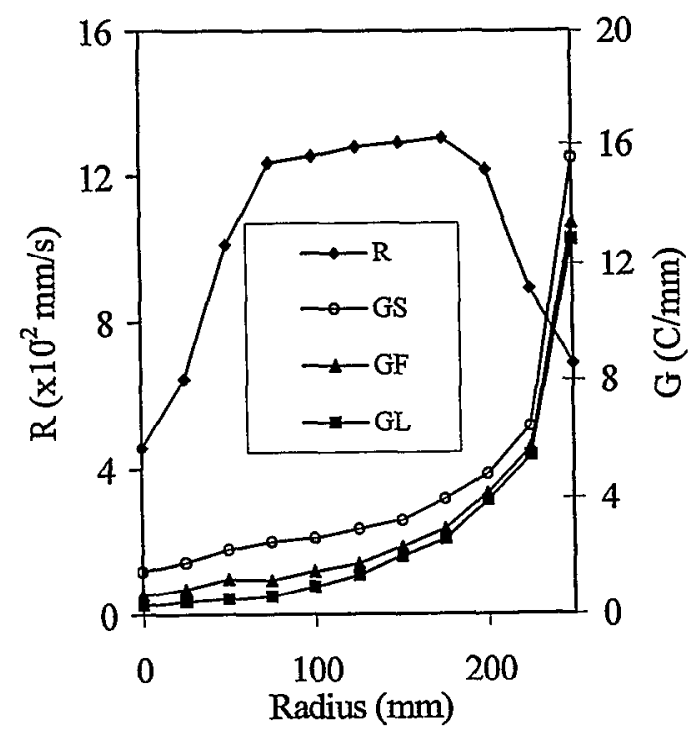

Figure 3 Thermal gradients at the liquidus, freckle and solidus temperatures and solidification rate in VAR IN718 (melt rate : $260 \mathrm{~kg} / \mathrm{hr}$ ) (after [17]).

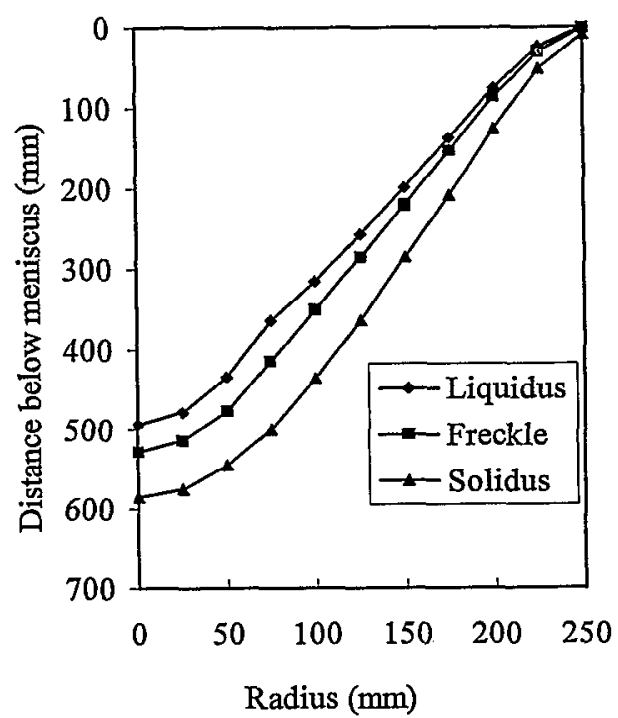

Figure 2 Pool depth vs. Radius in VAR IN718 shown by the isotherms for the liquidus, freckle and solidus temperatures. (260kg/hr melt rate) (after [17]).

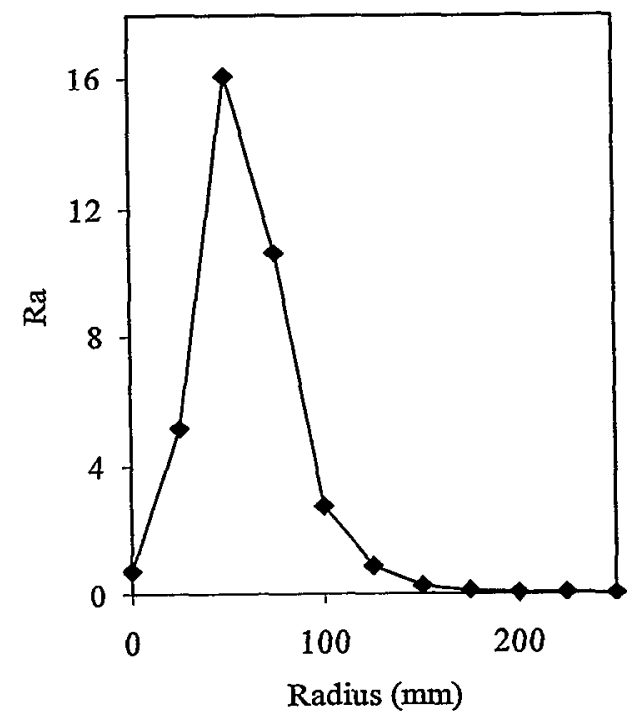

Figure 4 Rayleigh criteria profiles along the radius of VAR IN718 (melt rate: $260 \mathrm{~kg} / \mathrm{hr}$.) 


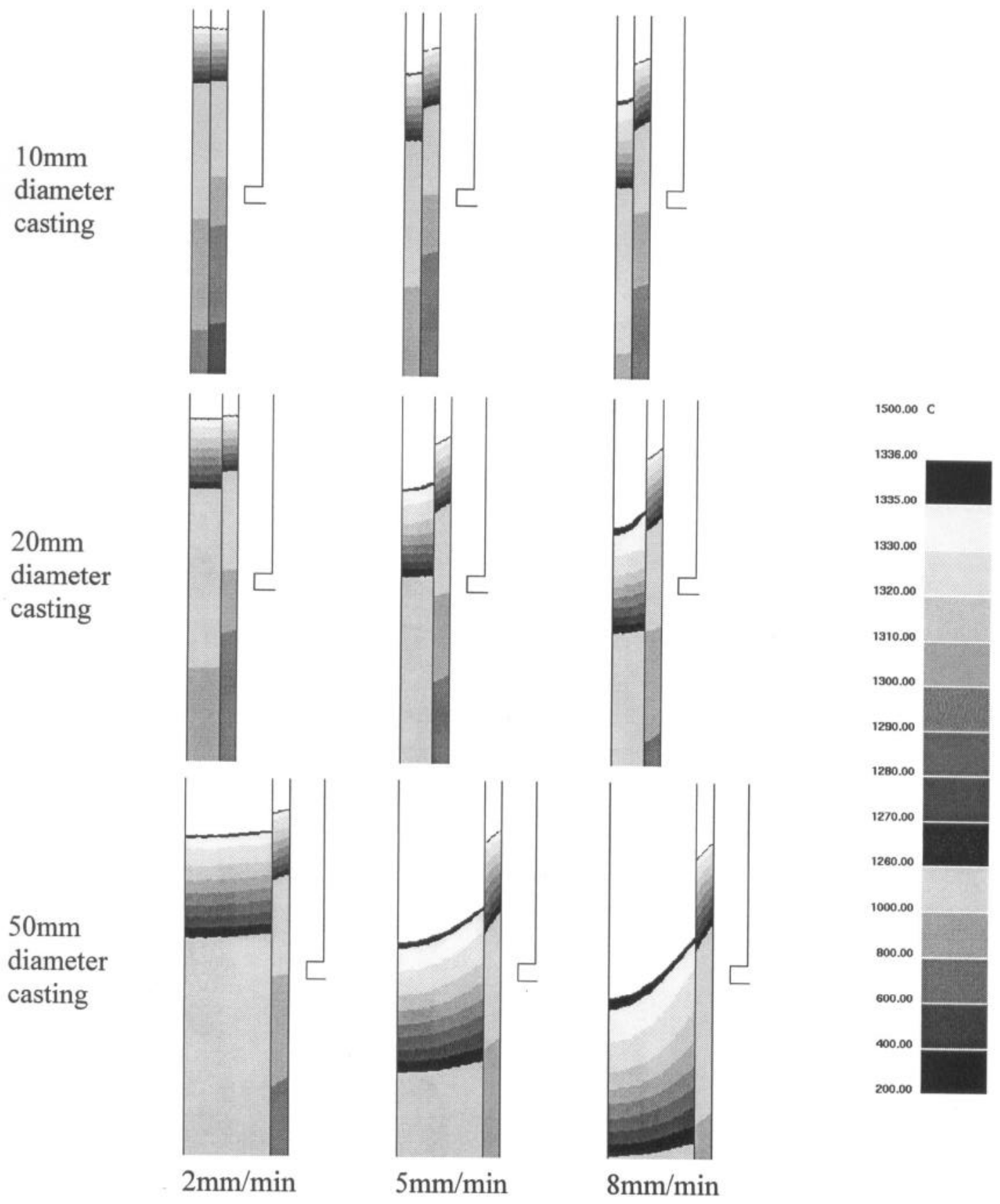

Figure 5 Numerical simulation of the influence of casting cross-sections and withdrawal rates on the growth front angle found in DS/SX castings. (Control temperature $1435^{\circ} \mathrm{C}$, after $130 \mathrm{~mm}$ withdrawal) (ProCAST simulation) 
Table 1 Compositions (in wt\%) and melting range of chosen alloys

\begin{tabular}{|l|c|l|}
\hline Alloy & \multicolumn{1}{|c|}{ Nominal Composition (wt\%) } & $\mathrm{T}_{\text {Sol }}-\mathrm{T}_{\mathrm{Liq}}\left({ }^{\circ} \mathrm{C}\right)$ \\
\hline CMSX-11B & $3.6 \mathrm{Al}, 7 \mathrm{Co}, 12.5 \mathrm{Cr}, 0.5 \mathrm{Mo}, 0.1 \mathrm{Nb}, 4.2 \mathrm{Ti}, 5 \mathrm{~W}, 5 \mathrm{Ta}, 0.04 \mathrm{Hf}, \mathrm{Bal} . \mathrm{Ni}^{(45)}$ & $1275-1336^{*}$ \\
\hline René 88 (2) & $2.1 \mathrm{Al}, 0.03 \mathrm{C}, 13 \mathrm{Co}, 16 \mathrm{Cr}, 4 \mathrm{Mo}, 0.7 \mathrm{Nb}, 3.7 \mathrm{Ti}, 4 \mathrm{~W}, 0.015 \mathrm{~B}, \mathrm{Bal} . \mathrm{Ni}^{(43)}$ & $1250-1355^{(43)}$ \\
\hline Nim 80A & $1.4 \mathrm{Al}, 0.03 \mathrm{~B}, 0.06 \mathrm{C}, 19.5 \mathrm{Cr}, 0.3 \mathrm{Mn}, 76.0 \mathrm{Ni}, 0.3 \mathrm{Si}, 2.4 \mathrm{Ti}, 0.06 \mathrm{Zr}^{(44)}$ & $1313-1379^{*}$ \\
\hline IN718 & $0.46 \mathrm{Al}, 0.031 \mathrm{C}, 0.2 \mathrm{Co}, 18.12 \mathrm{Cr}, 2.96 \mathrm{Mo}, 5.27 \mathrm{Nb}, 53.46 \mathrm{Ni}, 1 \mathrm{Ti}, 0.08 \mathrm{Si}, 18.24 \mathrm{Fe}{ }^{*}$ & $1253-1347^{*}$ \\
\hline IN718- LSi & $0.5 \mathrm{Al}, 0.008 \mathrm{C}, 0.001 \mathrm{Co}, 18 \mathrm{Cr}, 3 \mathrm{Mo}, 5.0 \mathrm{Nb}, 54.03 \mathrm{Ni}, 1 \mathrm{Ti}, 0.007 \mathrm{Si}, \mathrm{Bal} . \mathrm{Fe}$ & $1280-1354^{*}$ \\
\hline IN718-HiSi & & $1175-1206^{*}$ \\
\hline
\end{tabular}

* samples analyzed by the Special Metal Corporation.

** alloys provided by: Canon Muskegon Corp. (CMSX-11B); General Electric Corp. (René 88); Special Metal Corp. (IN718); Inco Alloys International (Nim 80A).

Table 3 Chemical analysis (measured by microprobe) of the matrix and freckles from some of the experimental samples. (wt\%)

\begin{tabular}{|c|c|c|c|c|c|c|c|c|}
\hline & \multicolumn{2}{|c|}{ IN718 } & \multicolumn{2}{c|}{ IN718-0.4Si } & \multicolumn{2}{c|}{ IN718HiSi } & \multicolumn{2}{c|}{ CMSX-11B } \\
\cline { 2 - 10 } & Matrix & Freckle & Matrix & Freckle & Matrix & Freckle & Matrix & Freckle \\
\hline $\mathrm{Al}$ & 0.37 & 0.40 & 0.41 & 0.27 & 0.38 & 0.33 & 2.93 & 3.32 \\
\hline $\mathrm{Si}$ & 0.23 & 0.27 & 0.50 & 0.97 & 0.62 & 1.35 & - & - \\
\hline $\mathrm{Ti}$ & 1.08 & 1.31 & 0.95 & 1.61 & 0.90 & 1.39 & 3.93 & 7.08 \\
\hline $\mathrm{Cr}$ & 18.48 & 17.98 & 18.67 & 15.90 & 18.58 & 16.08 & 11.34 & 5.59 \\
\hline $\mathrm{Fe}$ & 18.63 & 17.41 & 18.82 & 15.06 & 19.45 & 16.33 & - & - \\
\hline $\mathrm{Ni}$ & 53.94 & 53.0 & 53.42 & 53.06 & 53.41 & 51.88 & 59.02 & 61.75 \\
\hline $\mathrm{Nb}$ & 4.66 & 6.09 & 4.21 & 9.07 & 4.05 & 8.86 & 0.13 & 0.11 \\
\hline $\mathrm{Mo}$ & 3.07 & 3.54 & 3.04 & 4.05 & 2.86 & 3.79 & 0.48 & 0.26 \\
\hline $\mathrm{Co}$ & - & - & - & - & - & - & 5.51 & 4.49 \\
\hline $\mathrm{Hf}$ & - & - & - & - & - & - & 0.16 & 0.22 \\
\hline $\mathrm{Ta}$ & - & - & - & - & - & - & 6.23 & 9.4 \\
\hline $\mathrm{W}$ & - & - & - & - & - & - & 9.90 & 7.77 \\
\hline
\end{tabular}

Table 2 Threshold values for the freckle formation in some superalloys

\begin{tabular}{cc} 
Alloys & Critical Rayleigh Number \\
CMSX-11B & 0.88 \\
René88 & 0.90 \\
Nim80A & 0.85 \\
IN718-Si & 0.65 \\
Waspaloy & 0.95 \\
Mar-M247 & 0.86 \\
\hline
\end{tabular}


Table 2 Summary of the directional solidification experiments carried out on the tiltable Bridgman furnace.

\begin{tabular}{|c|c|c|c|c|c|c|c|}
\hline Alloy & Sample & $\begin{array}{c}\text { Furnace } T \\
\left({ }^{\circ} \mathrm{C}\right)\end{array}$ & Angle & $\begin{array}{l}\mathrm{G}_{\text {Liquidus }} \\
\left({ }^{\circ} \mathrm{C} / \mathrm{cm}\right)\end{array}$ & $\begin{array}{c}\mathrm{G}_{\text {Freckle }} \\
\left({ }^{\circ} \mathrm{C} / \mathrm{cm}\right)\end{array}$ & $\begin{array}{c}\mathrm{R} \\
(\mathrm{mm} / \mathrm{min})\end{array}$ & Freckling? \\
\hline CMSX-11B & $\begin{array}{l}\# 001 \\
\# 002 \\
\# 007 \\
\# 008 \\
\# 006 \\
\# 005 \\
\# 012 \\
\# 010 \\
\# 004 \\
\# 003 \\
\# 011 \\
\# 009\end{array}$ & $\begin{array}{l}1435 \\
1435 \\
1500 \\
1500 \\
1435 \\
1435 \\
1500 \\
1500 \\
1435 \\
1435 \\
1500 \\
1500 \\
\end{array}$ & $\begin{array}{l}0 \\
0 \\
0 \\
0 \\
\\
20 \\
20 \\
20 \\
20 \\
\\
35 \\
35 \\
35 \\
35 \\
\end{array}$ & $\begin{array}{c}23 \\
23 \\
30 \\
7 \\
\\
23 \\
7 \\
30 \\
7 \\
\\
23 \\
7 \\
30 \\
7 \\
\end{array}$ & $\begin{array}{l}27 \\
27 \\
33 \\
19 \\
\\
27 \\
18 \\
33 \\
19 \\
\\
27 \\
18 \\
33 \\
19 \\
\end{array}$ & $\begin{array}{l}1 \\
1 \\
1 \\
6 \\
1 \\
6 \\
1 \\
6 \\
\\
1 \\
6 \\
1 \\
6 \\
\end{array}$ & $\begin{array}{c}\text { no } \\
\text { no } \\
\text { no } \\
\text { no } \\
\text { yes } \\
\text { no } \\
\text { yes } \\
\text { no } \\
\text { yes } \\
\text { no } \\
\text { yes } \\
\text { no }\end{array}$ \\
\hline René 88 & $\begin{array}{l}\# 101 \\
\# 102 \\
\# 103 \\
\# 104 \\
\# 105 \\
\end{array}$ & $\begin{array}{l}1400 \\
1465 \\
1400 \\
1465 \\
1400 \\
\end{array}$ & $\begin{array}{c}35 \\
35 \\
20 \\
20 \\
0 \\
\end{array}$ & $\begin{array}{c}9 \\
26 \\
9 \\
26 \\
11 \\
\end{array}$ & $\begin{array}{l}18 \\
32 \\
18 \\
32 \\
19 \\
\end{array}$ & $\begin{array}{l}6 \\
1 \\
6 \\
1 \\
1 \\
\end{array}$ & $\begin{array}{c}\text { no } \\
\text { yes } \\
\text { no } \\
\text { yes } \\
\text { yes } \\
\end{array}$ \\
\hline Nim 80A & $\begin{array}{l}\# 201 \\
\# 202 \\
\# 203 \\
\# 205 \\
\# 204\end{array}$ & $\begin{array}{l}1435 \\
1500 \\
1435 \\
1500 \\
1435 \\
\end{array}$ & $\begin{array}{l}35 \\
35 \\
20 \\
20 \\
0\end{array}$ & $\begin{array}{l}11 \\
26 \\
11 \\
26 \\
15\end{array}$ & $\begin{array}{l}17 \\
30 \\
17 \\
30 \\
21\end{array}$ & $\begin{array}{l}6 \\
1 \\
6 \\
1 \\
1\end{array}$ & $\begin{array}{l}\text { no } \\
\text { yes } \\
\text { no } \\
\text { yes } \\
\text { yes }\end{array}$ \\
\hline IN718 & $\begin{array}{l}\# 301 \\
\# 302 \\
\# 303 \\
\# 304 \\
\# 305\end{array}$ & $\begin{array}{l}1400 \\
1465 \\
1400 \\
1465 \\
1400\end{array}$ & $\begin{array}{c}35 \\
35 \\
20 \\
20 \\
0\end{array}$ & $\begin{array}{l}10 \\
26 \\
10 \\
26 \\
14\end{array}$ & $\begin{array}{l}16 \\
31 \\
16 \\
31 \\
20\end{array}$ & $\begin{array}{l}6 \\
1 \\
6 \\
1 \\
1\end{array}$ & $\begin{array}{c}\text { no } \\
\text { yes(underside) } \\
\text { no } \\
\text { yes(underside) } \\
\text { yes }\end{array}$ \\
\hline IN718LSi & $\begin{array}{l}\# 401 \\
\# 402 \\
\# 403 \\
\# 404 \\
\# 405\end{array}$ & $\begin{array}{l}1435 \\
1500 \\
1435 \\
1500 \\
1435 \\
\end{array}$ & $\begin{array}{c}35 \\
35 \\
20 \\
20 \\
0\end{array}$ & $\begin{array}{l}15 \\
29 \\
15 \\
29 \\
20 \\
\end{array}$ & $\begin{array}{l}22 \\
33 \\
22 \\
33 \\
25 \\
\end{array}$ & $\begin{array}{l}6 \\
1 \\
6 \\
1 \\
1 \\
\end{array}$ & $\begin{array}{c}\text { no } \\
\text { yes(underside) } \\
\text { no } \\
\text { no } \\
\text { no } \\
\end{array}$ \\
\hline IN718HiSi & $\begin{array}{l}\# 501 \\
\# 502 \\
\# 503 \\
\# 504 \\
\# 505\end{array}$ & $\begin{array}{l}1400 \\
1465 \\
1400 \\
1465 \\
1400\end{array}$ & $\begin{array}{c}35 \\
35 \\
20 \\
20 \\
0\end{array}$ & $\begin{array}{c}9 \\
35 \\
9 \\
35 \\
31\end{array}$ & $\begin{array}{l}17 \\
38 \\
17 \\
38 \\
35\end{array}$ & $\begin{array}{l}6 \\
1 \\
6 \\
1 \\
1 \\
\end{array}$ & $\begin{array}{c}\text { no } \\
\text { yes } \\
\text { no } \\
\text { yes } \\
\text { yes }\end{array}$ \\
\hline NN718-0.1Si & $\# 601$ & 1465 & 35 & & & 1 & yes(underside) \\
\hline $\mathrm{IN} 718-0.2 \mathrm{Si}$ & $\# 701$ & 1465 & 35 & & & 1 & yes(underside) \\
\hline $\mathrm{IN} 718-0.3 \mathrm{Si}$ & $\# 801$ & 1465 & 35 & & & 1 & yes(underside) \\
\hline IN718-0.4Si & $\# 901$ & 1465 & 35 & & & 1 & yes(underside) \\
\hline
\end{tabular}

*: "yes" means freckles occur on the upside surface of an inclined sample or the surface of a vertical sample;

"yes(underside)" means freckles occur on the underside surface of an inclined sample. 